\title{
Cholestasis in Crohn's disease: A diagnostic challenge
}

\author{
Nir Hilzenrat mD, Esther lamoureux mD, Averell Sherker mD, Albert CoHen mD
}

\begin{abstract}
N Hilzenrat, E lamoureux, A Sherker, A Cohen. Cholestasis in Crohn's disease: A diagnostic challenge. Can J Gastroenterol 1997;11(1):35-37. A 24-year-old male with Crohn's disease who developed three independent episodes of cholestatic liver disease over an eight-year period is described. The first episode was related to an idiosyncratic drug reaction while on sulfasalazine. The second episode, at the time of an exacerbation of his colitis, was characterized by moderate portal inflammation on liver biopsy and resolved quickly while he was on corticosteroid therapy. The most recent episode, occurring when the bowel disease was quiescent, was due to granulomatous hepatitis and resolved clinically with no specific therapy. Because numerous potentially serious hepatobiliary complications have been associated with inflammatory bowel disease, prompt and aggressive investigation in these instances is recommended.
\end{abstract}

Key Words: Cholestasis, Crohn's disease, Sulfasalazine

\section{Choléstase dans la maladie de Crohn : un défi} diagnostique

RÉSUMÉ : On décrit ici le cas d'un jeune patient de 24 ans atteint de maladie de Crohn qui a présenté trois épisodes distincts de maladie hépatique cholestatique. Le premier épisode avait rapport avec une réaction médicamenteuse idiosyncrasique associée à la sulfasalazine. Le deuxième épisode, survenu au moment d'une exacerbation de sa colite, a été caractérisé par une inflammation portale modérée à la biopsie hépatique et est rentré rapidement dans l'ordre avec la corticothérapie. L'épisode le plus récent, survenu alors que la maladie intestinale était quiescente, a été attribuable à une hépatite granulomateuse et est cliniquement rentré dans l'ordre sans traitement spécifique. À cause des nombreuses complications hépatobiliaires graves potentielles associées à la maladie inflammatoire de l'intestin, il est recommandé de procéder sans délais à des examens énergiques dans de tels cas.
$\mathrm{C}$ rohn's disease is a chronic inflammatory condition that may involve any part of the gastrointestinal tract and is often associated with numerous extra-intestinal manifestations. Although hepatobiliary disease is a known potential complication, it is not a frequent clinical occurrence. It may nonetheless lead to significant morbidity and mortality, including fatty liver, primary sclerosing cholangitis, cholangiocarcinoma, gallstones, hepatic abscesses, granulomas and drug reactions (1).

We report a case of a 24-year-old male with Crohn's colitis who presented with fever, chills and cholestasis.

\section{CASE PRESENTATION}

The patient, a 24-year-old Caucasian male, presented with a five-day history of fever and chills.

At age 16 he developed bloody diarrhea and fever, and had physical findings of erythema nodosum and a perianal fistula. The investigation confirmed Crohn's colitis. The patient responded to medical treatment with prednisone and metronidazole.

One year later he presented with an exacerbation of his illness and was treated with sulfasalazine. One month after initiation of this treatment, he developed fever, skin rash, jaundice and eosinophilia. These were attributed to an idio-

Division of Gastroenterology and Department of Pathology, Sir Mortimer B Davis-Jewish General Hospital, McGill University, Montreal, Quebec

Correspondence and reprints: Dr Albert Cohen, Division of Gastroenterology, Sir Mortimer B Davis-Jewish General Hospital, 3755 St

Catherine Road, Montreal, Quebec H3T 1E2. Telephone 514-340-8223, fax 514-340-8282

Received for publication May 6, 1996. Accepted May 22, 1996 


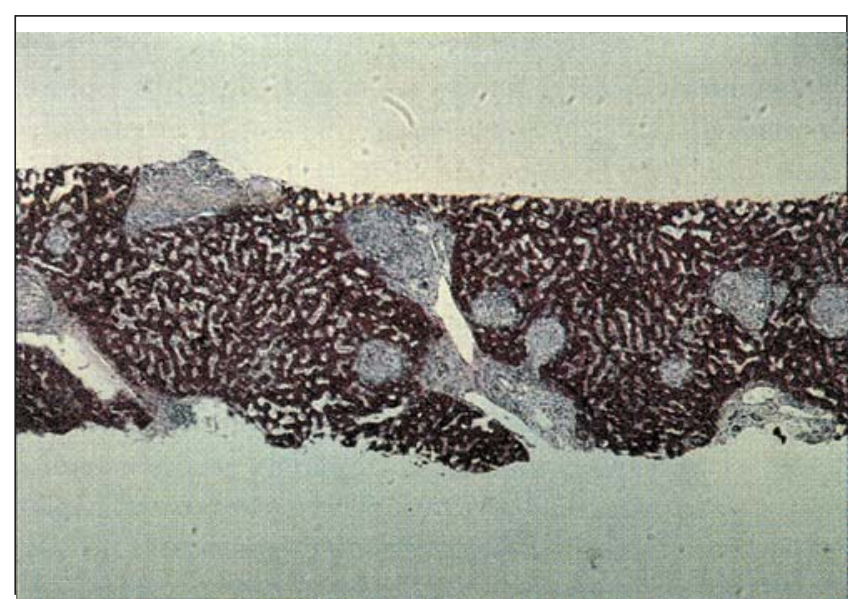

Figure 1) Photomicrograph of liver biopsy. Numerous granulomas are scattered throughout the liver core (periodic acid-Schiff stain, x19)

syncratic reaction secondary to sulfasalazine, which was discontinued; his symptoms then resolved.

The following year the patient again developed bloody diarrhea, fever and jaundice, along with a rise in his liver transaminases. At presentation aspartate aminotransferase (AST) and alanine aminotransferase (ALT) were 1279 and $1225 \mathrm{U} / \mathrm{L}$ (normal for both 5 to 40), respectively, with an alkaline phosphatase of $874 \mathrm{U} / \mathrm{L}$ (normal 30 to 110 ). Within one week, the AST regressed to $68 \mathrm{U} / \mathrm{L}$, ALT to $353 \mathrm{U} / \mathrm{L}$ and alkaline phosphatase to $447 \mathrm{U} / \mathrm{L}$. These normalized completely within six weeks. Liver biopsy revealed mild to moderate inflammation of the portal zones with piecemeal necrosis. There was canalicular proliferation and fibrosis of one portal space.

A percutaneous transhepatic cholangiogram was normal. Viral serology and autoantibody studies were negative. The patient was diagnosed with idiopathic chronic active hepatitis. He was treated with a four-month course of oral prednisone for his bowel disease and experienced progressive improvement in his biochemical and clinical parameters, with resolution of fever and jaundice.

At age 22 he entered a phase of frequent recurrences of bowel disease and required treatment with various aminosalicylic acid preparations: metronidazole, prednisone and, eventually, 6-mercaptopurine. Immunosuppressive therapy was eventually discontinued after two years because of satisfactory, sustained remission.

Five days before the admission reported here, the patient presented with fever, chills and 'flu-like symptoms. He denied diarrhea, hematochezia or abdominal pain. Similarly, he denied any joint pain, ocular symptoms or buccal lesions. Physical examination was unremarkable.

Hemoglobin, white blood cell count and platelets were normal. Alkaline phosphatase was elevated at $593 \mathrm{U} / \mathrm{L}$ (normal 30 to 110), gamma-glutamyl transpeptidase was $220 \mathrm{U} / \mathrm{L}$ (normal 35 to 60), alanine transaminase was $66 \mathrm{U} / \mathrm{L}$ (normal 35 to 40 ) and total bilirubin was $7 \mu \mathrm{mol} / \mathrm{L}$ (normal 33 to 17 ). All other biochemical parameters were normal. Serology for cytomegalovirus and hepatitis $\mathrm{A}, \mathrm{B}$ and $\mathrm{C}$ viruses was nega-

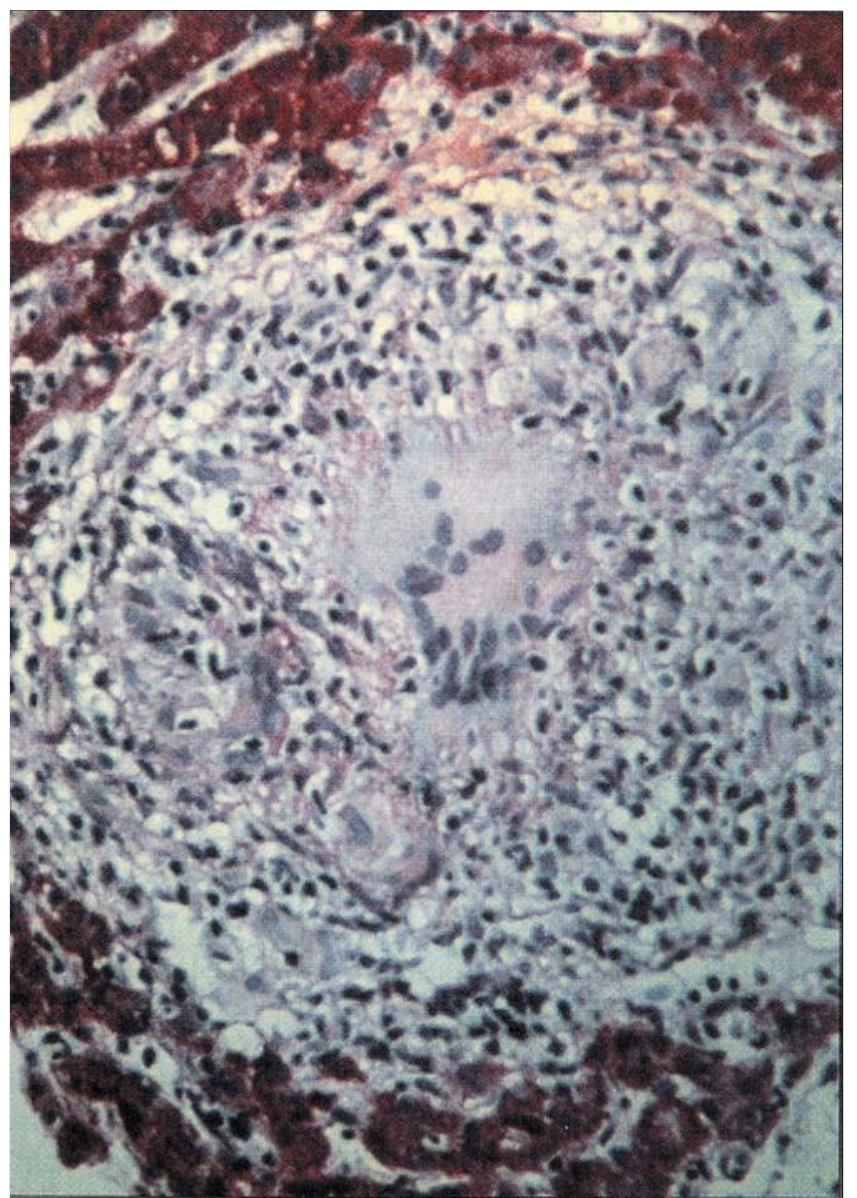

Figure 2) Cluster of histiocytes admixed with multinucleated giant cell and lymphocytes forms the granulomas (periodic acid-Schiff stain, $x 166$ )

tive, as was serology for antimitochondrial antibodies, antismooth muscle antibodies, antinuclear antibodies and rheumatoid factor. Results from a chest $\mathrm{x}$-ray and abdominal ultrasound were within normal limits. Because of persistent cholestasis, an endoscopic retrograde cholangiopancreatography (ERCP) was performed. It revealed a normal extrahepatic and intrahepatic biliary tree. A percutaneous biopsy of the liver revealed a globally normal architecture, with absence of active inflammation (Figures 1,2). Numerous nonnecrotizing granulomas were seen throughout the hepatic lobules. Special stains were negative for mycobacteria and fungi.

Six days after initial presentation, the patient's symptoms resolved entirely without any specific therapy. He has remained asymptomatic in follow-up for over one year. During this period his treatment with mesalamine was maintained at $1.5 \mathrm{~g} /$ day.

\section{DISCUSSION}

The diagnosis of Crohn's disease in this patient was previously established endoscopically and histologically.

He manifested three independent episodes of cholestatic liver disease related to inflammatory bowel disease. The first was likely an idiosyncratic reaction to sulfasalazine, whereas the second and third were characterized by histological evi- 
dence of mild portal inflammation and hepatic granulomas, respectively. The second episode resolved quickly while the patient was on corticosteroid therapy. The third episode was self-limited. This case illustrates several of the numerous potential causes of cholestatic liver disease associated with Crohn's disease enumerated in Table 1 .

The diagnostic approach employed was to first rule out sepsis or a liver abscess. Although the biochemical abnormalities noted in this case could evoke these diagnoses $(1,2)$, the negative blood cultures and ultrasound did not support this. The next diagnostic step was an ERCP to rule out large duct biliary disease, particularly primary sclerosing cholangitis, but no disease was found. The final diagnostic step was a liver biopsy to rule out conditions such as hepatic steatosis, chronic active hepatitis and small duct primary sclerosing cholangitis (1). The biopsy demonstrated hepatic granulomas in the absence of necroinflammatory disease.

A granuloma is a focal accumulation of macrophages that undergoes transformation to predominantly secretory cells in response to ingested antigens $(3,4)$. Such granulomas may result from infections, immunological aberrations, enzyme defects, drugs and neoplasia, yet $13 \%$ are classified as idiopathic (3-5). The most common causes of hepatic granulomas include sarcoidosis, tuberculosis and histoplasmosis $(4,5)$. Fever is a predominant feature of granulomatous hepatitis in up to $44 \%$ of patients (6). Abnormal laboratory tests are not diagnostic but serum alkaline phosphatase tends to be elevated out of proportion with serum transaminases, and elevation of erythrocyte sedimentation rate is common (3).

Although it is accepted that granulomas may be found in the liver in Crohn's disease, the prevalence, clinical manifestations and relationship to disease activity are not well established. Dordal et al (7) studied 27 patients with Crohn's disease and described five cases of liver granulomas. A second series by Eade and colleagues (8) followed 100 patients prospectively over 18 months; 49 liver biopsies were obtained and three demonstrated hepatic granulomas. Those authors also reviewed 20 liver biopsies in patients who underwent a colectomy for Crohn's colitis and found three cases of hepatic granulomas. Six- and 12-year follow-up on two of these three patients revealed a diminishing number of hepatic granulomas postoperatively (9). Maurer et al (10) REFERENCES

1. Chapman RW, Angus PW. The effect of gastrointestinal disease on the liver and biliary tract. In: McIntyre N, Benhamou JP, Bircher J, Rizzetto M, Rodes J, eds. Oxford Textbook of Clinical Hepatology. Oxford: Oxford University Press, 1991:1170-3.

2. Zimmerman HJ, Fang M, Utili R, Seeff LB. Jaundice due to bacterial infection. Gastroenterology 1979;77:362-74.

3. James DG, Scheuer PJ. Hepatic granulomas. In: McIntyre N, Benhamou JP, Bircher J, Rizzetto M, Rodes J, eds. Oxford Textbook of Clinical Hepatology. Oxford: Oxford University Press, 1991:750-8.

4. Fauci AS, Wolff SM. Granulomatous hepatitis. Prog Liver Dis 1976;5:609-21.

5. Sortin JS, Walher RC. Granulomatous hepatitis: A retrospective review of 88 cases at the Mayo Clinic. Mayo Clin Proc 1991;61:914-8.

\section{TABLE 1}

\section{Major hepatobiliary complications of Crohn's disease}

Biliary

Primary sclerosing cholangitis

Small bile ducts

Large bile ducts

Intrahepatic

Extrahepatic

Cholangiocarcinoma

Cholelithiasis

Hepatocellular

Hepatic steatosis

Chronic active hepatitis

Drug-induced liver disease

Granulomatous hepatitis

Hepatic abscesses

described a case of granulomatous hepatitis and regional enteritis in which the granulomas regressed after resection of the inflamed intestine.

Although these studies substantiate the coexistence of Crohn's disease and liver granulomas, no systematic search was undertaken to rule out other potential causes of granulomas. The incidence and prevalence of this hepatic complication in Crohn's disease remain unclear.

In the present case, the acute cholestatic liver disease associated with hepatic granulomas was not clearly correlated with disease activity and symptomatically resolved spontaneously.

\section{CONCLUSIONS}

This case illustrates several distinct hepatic complications of Crohn's disease occurring over the course of a single patient's illness. These individual manifestations were transient without any evidence of progressive liver disease.

In view of the numerous and potentially serious hepatobiliary complications of inflammatory bowel disease, the onset of cholestasis should warrant a prompt and aggressive investigation as outlined in this case report.

6. Simon HB, Wolff SM. Granulomatous hepatitis and prolonged fever of unknown origin: A study of 13 patients. Medicine 1973;52:1-21.

7. Dordal E, Glagov S, Kirsner JB. Hepatic lesions in chronic inflammatory bowel disease. Clinical correlations with liver biopsy diagnosis in 103 patients. Gastroenterology 1967;52:239-53.

8. Eade MN, Cooke WT, Williams JA. A study of 100 consecutive patients. Scand J Gastroenterol 1971;6:199-204.

9. Eade MN, Cooke WT, Brook BN, Thompson H. Liver disease in Crohn's colitis. A study of 21 consecutive patients having colectomy. Ann Intern Med 1971;74:518-28.

10. Maurer LH, Hughes RW, Folley JH, Mosenthal WT. Granulomatous hepatitis associated with regional enteritis. Gastroenterology 1967;53:301-5. 


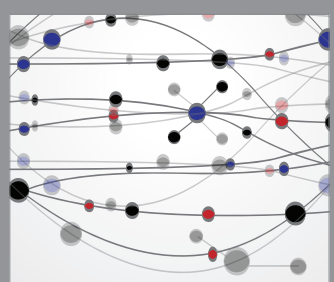

The Scientific World Journal
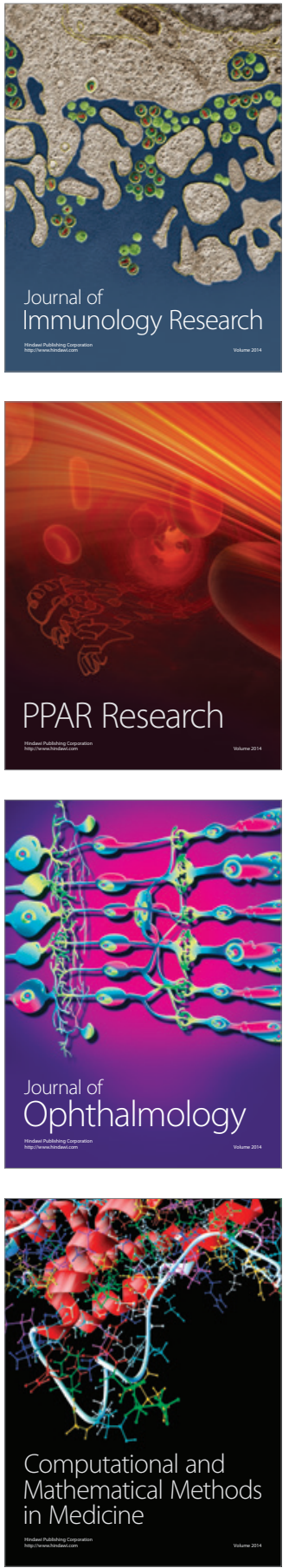

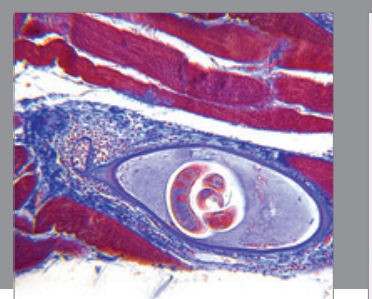

Gastroenterology Research and Practice

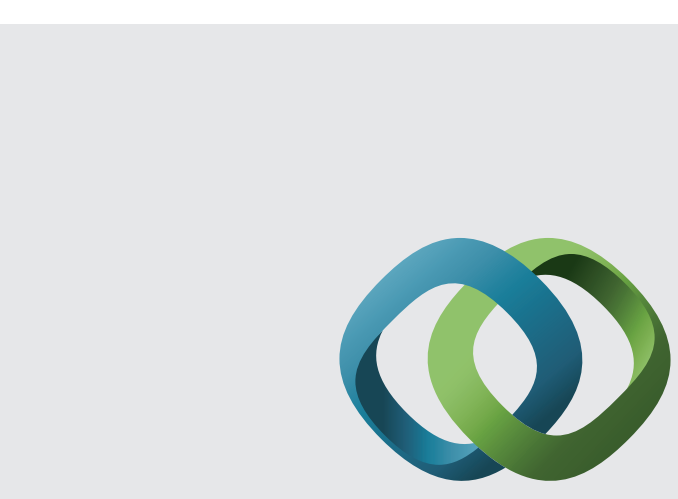

\section{Hindawi}

Submit your manuscripts at

http://www.hindawi.com
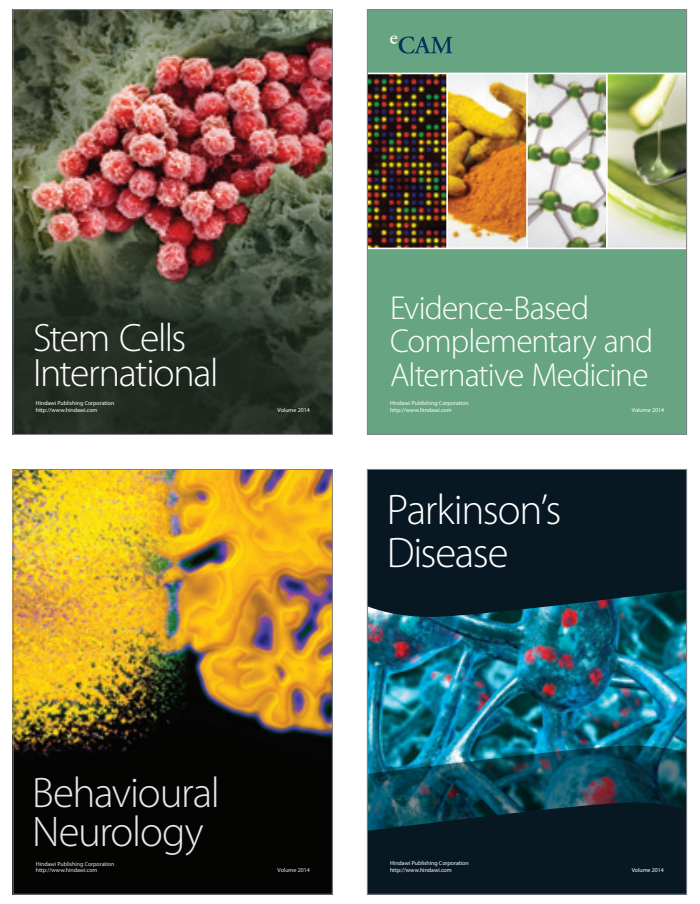
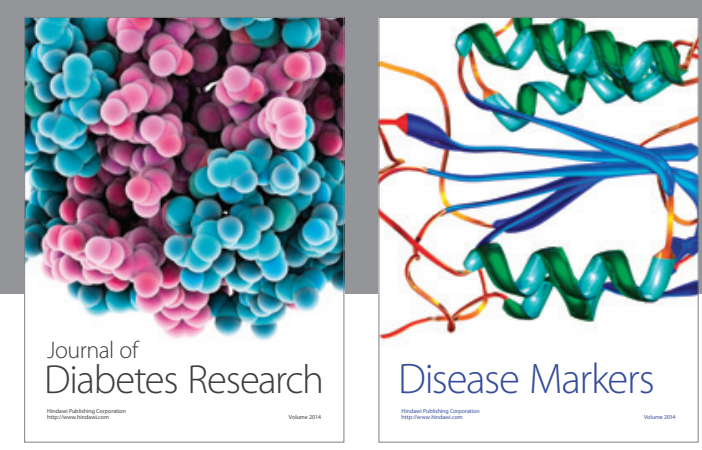

Disease Markers
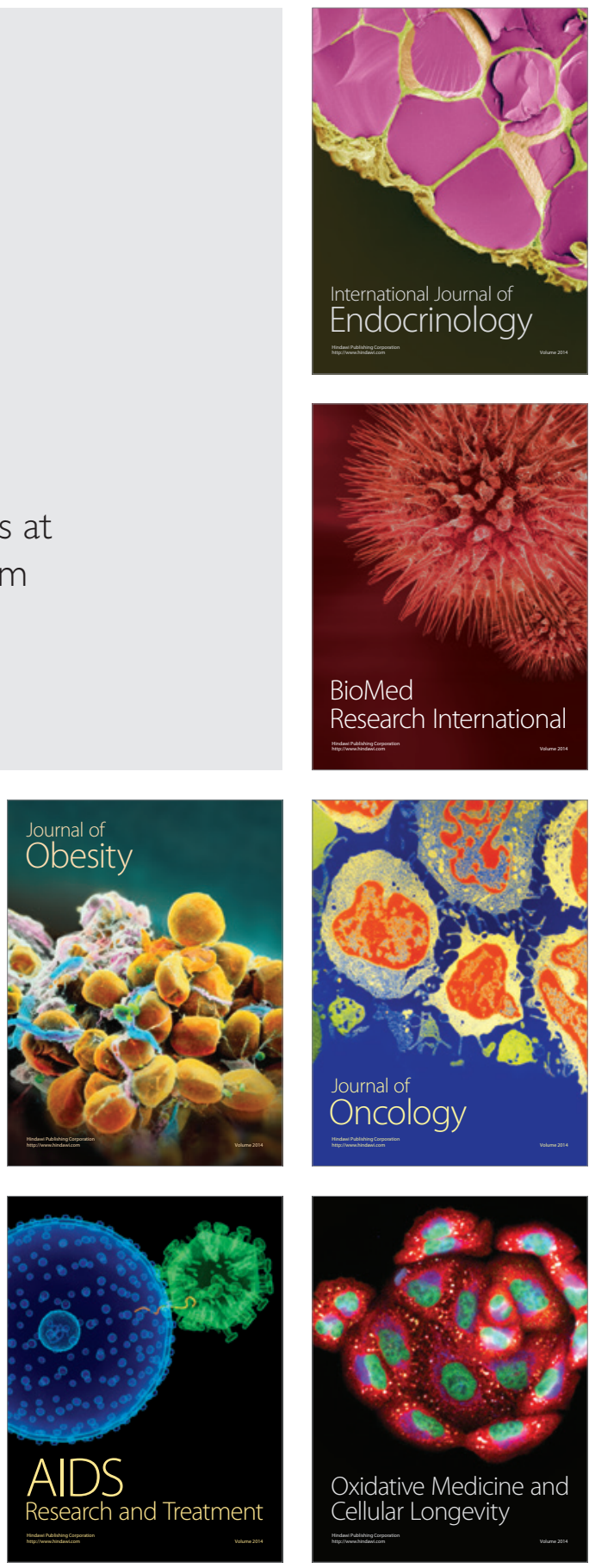